Vol 12, Issue 4, 2019

\title{
STABILITY-INDICATING HIGH-PERFORMANCE THIN-LAYER CHROMATOGRAPHY METHOD FOR SIMULTANEOUS ESTIMATION OF FORMOTEROL FUMARATE DIHYDRATE AND FLUTICASONE PROPIONATE IN BULK DRUG AND PHARMACEUTICAL DOSAGE FORM
}

\author{
RAJASHI B PHARATE ${ }^{1}$, SUNEELA S DHANESHWAR ${ }^{2 *}$ \\ ${ }^{1}$ Department of Quality Assurance, Bharati Vidyapeeth University, Poona College of Pharmacy, Pune, Maharashtra, India. ${ }^{2}$ Department \\ of Pharmaceutical Chemistry, Amity Institute of Pharmacy, Amity University Uttar Pradesh, Lucknow, Uttar Pradesh, India. Email: \\ sdhaneshwar1@lko.amity.edu
}

Received: 07 January 2019, Revised and Accepted: 25 February 2019

ABSTRACT

Objective: The objective of the present work was to develop validated stability-indicating high-performance thin-layer chromatographic method for simultaneous estimation of formoterol fumarate dihydrate (FFD) and fluticasone propionate (FP) in bulk drug and pharmaceutical dosage form.

Methods: Pre-coated silica gel aluminum plates 60 F-254 were used as stationary phase. The mixture of toluene:ethyl acetate:formic acid (98\%) $(6: 4: 0.1 ; \mathrm{v} / \mathrm{v} / \mathrm{v})$ was used as a mobile phase. The densitometric quantification was carried out at $233 \mathrm{~nm}$. The method was validated according to the ICH guidelines. The specificity and stability indicating the capability of the method were proven though degradation studies. Both drugs were subjected to acid $(0.1 \mathrm{~N} \mathrm{HCl})$ and base $(0.1 \mathrm{~N} \mathrm{NaOH})$ hydrolysis, oxidation $\left(3 \% \mathrm{v} / \mathrm{v} \mathrm{H}_{2} \mathrm{O}_{2}\right)$, photolytic, and neutral degradation conditions.

Results: The selected mobile phase resolved peaks of FFD and FP with $\mathrm{R}_{\mathrm{f}}$ values $0.27 \pm 0.10$ and $0.64 \pm 0.10$, respectively. Determination coefficients of calibration curves were found to be 0.998 and 0.999 in the range of $1-3.5 \mu \mathrm{g} /$ spot and $10-60 \mu \mathrm{g} / \mathrm{spot}$ for FFD and FP with an accuracy of $99.09 \%$ for FFD and $99.20 \%$ for FP. The degradation products of FFD and FP were resolved from the pure drug with significant differences in their retention factor values.

Conclusion: The developed method is simple, accurate and can be successfully applied for quantification of FFD and FP in bulk drug and pharmaceutical dosage form, contributing to improve the quality control and assure the therapeutic efficacy.

Keywords: Formoterol fumarate dihydrate, Fluticasone propionate, High-performance thin-layer chromatography, Stability-indicating method, Validation.

(C) 2019 The Authors. Published by Innovare Academic Sciences Pvt Ltd. This is an open access article under the CC BY license (http://creativecommons. org/licenses/by/4. 0/) DOI: http://dx.doi.org/10.22159/ajpcr.2019.v12i4.31279

\section{INTRODUCTION}

Inhalation is currently the preferred route of drug delivery in asthma in accordance with a global initiative for asthma guideline [1], as it allows the release of drug directly to the site where the action is needed, thus minimizing systemic side effect. Inhaled corticosteroid in combination with a long-acting $\beta 2$-agonist is the gold standard for the management of persistent asthma, with maximal local targeting and minimal systemic side effects. Formoterol fumarate dihydrate (FFD) is a longacting selective $\beta-2$ agonist used as a bronchodilator in the treatment of asthma. Chemically, FFD is a (E)-but-2-enedioic acid; N-[2-hydroxy5-[(1S)-1-hydroxy-2-[[(2S)-1-(4-methoxyphenyl) propan-2-yl] amino] ethyl] phenyl] formamide $[2,3]$.

Fluticasone propionate (FP) is chemically 6 $\alpha$, 9-Difluoro-17-

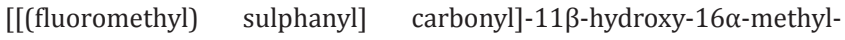
3-oxoandrosta-1, 4-dien-17 $\alpha$-ylpropanoate. FP is a tri-fluorinated glucocorticoid specifically designed to provide enhanced antiinflammatory effect $[2,4]$. Both drugs are official in IP, BP, EP, and USP [5-8]. The chemical structures of FFD and FP [8] are shown in Fig. $1 \mathrm{a}$ and $\mathrm{b}$, respectively.

Literature survey for FFD and FP revealed that various analytical methods using techniques such as high-performance liquid chromatography [9-20], spectrophotometry [18,21-25], and highperformance thin-layer chromatography (HPTLC) $[19,26]$ were reported for quantitative determination of single or multi-component systems. Gowekar and Wadher reported HPTLC method for simultaneous estimation of FFD and FP, but no degradation profile has been stated in the literature [27]. To the best of our knowledge, there is no stability indicating HPTLC method reported for the simultaneous estimation of FFD and FP in bulk drug and pharmaceutical dosage form.

Hence, the objective of the present work was to develop and validate the stability indicating HPTLC method for simultaneous estimation of FFD and FP in bulk drug and pharmaceutical dosage form.

\section{METHODS}

Chemicals and reagents

Gift samples of FFD and FP were procured from Vamsi Laboratories Pvt. Ltd. Solapur, Maharashtra, India. The pharmaceutical formulation of capsule Maxiflo-100 Rotacaps containing $6 \mu \mathrm{g}$ of FFD and $100 \mu \mathrm{g}$ of FP manufactured by Cipla Ltd. was procured from the market. All analytical grade chemicals and reagents used for the analysis were purchased from Merck, Mumbai, India.

\section{Instrumentation}

Pre-coated silica gel aluminum plates $60 \mathrm{~F}-254(20 \mathrm{~cm} \times 10 \mathrm{~cm}, 250 \mu \mathrm{m}$ thickness, E. Merck, Darmstadt, Germany) supplied by Anchrom, Mumbai were used. The sampling was done by automated TLC sampler Linomat V applicator (Camag, Muttenz, Switzerland) which was controlled by Win-Cats software (V 3.15, Camag, Muttenz, Switzerland). The standard and sample solutions were spotted in the form of bands of width $6 \mathrm{~mm}$ with a Camag $100 \mu \mathrm{L}$ sample (Hamilton, Bonaduz, Switzerland) syringe. Linear ascending development was carried out in a twin trough glass chamber $(20 \mathrm{~cm} \times 10 \mathrm{~cm}, 10 \mathrm{~cm} \times 10 \mathrm{~cm}$ Camag, Muttenz, Switzerland). The mobile phase consisted of toluene:ethyl acetate:formic acid (98\%) 


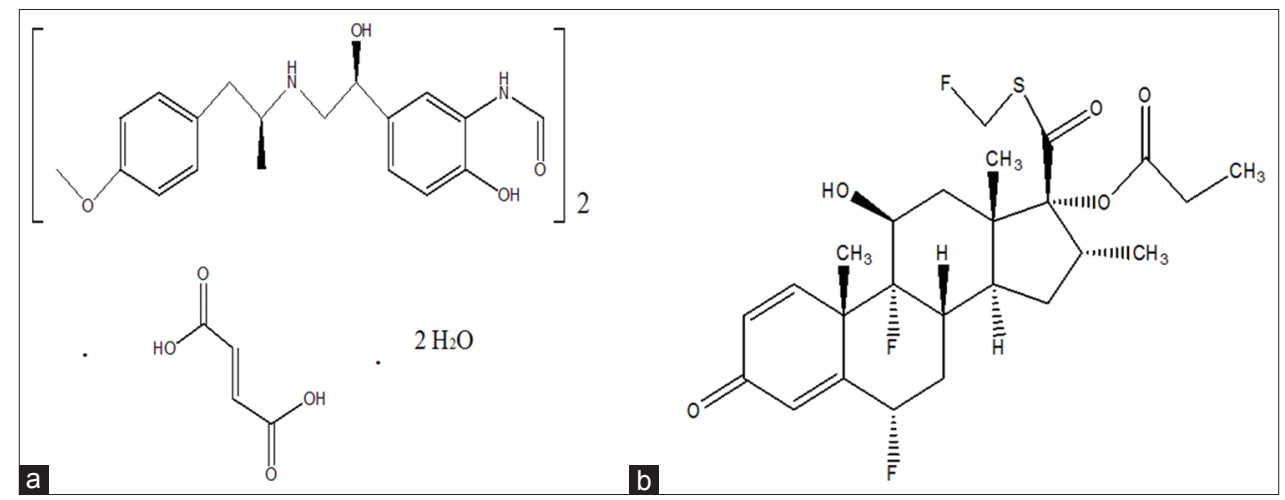

Fig. 1: (a) Chemical structure of formoterol fumarate dihydrate. (b) Chemical structure of fluticasone propionate

(6:4:0.1; v/v/v). The developing solvent was run up to $80 \mathrm{~mm}$ and development was performed at room temperature $\left(25^{\circ} \mathrm{C} \pm 2^{\circ} \mathrm{C}\right)$ at a relative humidity of $60 \% \pm 5 \%$. The development time was $20 \mathrm{~min}$. Plates were scanned at $233 \mathrm{~nm}$ with CAMAG TLC scanner 3. Deuterium lamp emitting a continuous UV spectrum between 200 and $400 \mathrm{~nm}$ was used as a source of radiation.

\section{HPTLC method and chromatographic conditions}

Preparation of standard stock solutions

Accurately weighed $10 \mathrm{mg}$ of FFD was transferred to $10 \mathrm{ml}$ volumetric flask, dissolved and diluted up to the mark with methanol $(1 \mathrm{mg} / \mathrm{ml})$.

Accurately weighed $10 \mathrm{mg}$ of FP was transferred to $10 \mathrm{ml}$ volumetric flask, dissolved and diluted up to the mark with chloroform $(1 \mathrm{mg} / \mathrm{ml})$.

\section{Preparation of sample solution}

Powder from 20 capsules (Maxiflo-100 Rotacaps containing $6 \mu \mathrm{g}$ of FFD and $100 \mu \mathrm{g}$ of FP per capsule) were weighed, their average weight determined (3.038 $\mathrm{mg}$ ) and crushed to fine powder. The quantity of powder equivalent to $10 \mathrm{mg}$ of FP and $0.6 \mathrm{mg}$ of FFD was transferred into a $10 \mathrm{ml}$ volumetric flask containing $5 \mathrm{ml}$ of methanol and mixed well. The solution was ultrasonicated for $20 \mathrm{~min}$, and then diluted to $10 \mathrm{ml}$ with methanol. The solution was filtered through Whatman filter paper $(0.45 \mu \mathrm{m})$. The amount of each drug present in the sample was determined by comparing mean peak areas with that of the standard.

\section{Prewashing of plates}

Densitometric estimation was carried out on $20 \mathrm{~cm} \times 10 \mathrm{~cm}$ pre-coated silica gel $60 \mathrm{~F}-254$ plates from E. Merck. The plates were pre-washed with methanol, dried and activated for $15 \mathrm{~min}$ at $110^{\circ} \mathrm{C}$ before chromatography.

\section{Selection of the solvent}

Methanol and chloroform were selected as solvents for preparing sample solutions.

\section{Selection of stationary phase}

Identification and separation of FFD and FP were carried out on $20 \mathrm{~cm} \times 10 \mathrm{~cm}, 10 \mathrm{~cm} \times 10 \mathrm{~cm}$, pre-coated silica gel aluminum plates 60 F-254 (250 $\mu$ m thickness E. Merck, Darmstadt, Germany).

\section{Sample application}

The standard and formulation solution of FFD and FP was spotted on pre-coated TLC plates in the form of narrow bands of length $6 \mathrm{~mm}$, at $8 \mathrm{~mm}$ from the bottom, and $10 \mathrm{~mm}$ distance between two bands. Samples were applied under continuous drying stream of nitrogen gas at constant application rate of $150 \mathrm{nl} / \mathrm{s}$.

\section{Selection of wavelength}

An evaluation was performed by linear regression of peak areas determined by UV absorption as a function of sample analysis at $233 \mathrm{~nm}$ using methanol as a blank solution. The selection of detection wavelength is shown in Fig. 2 .

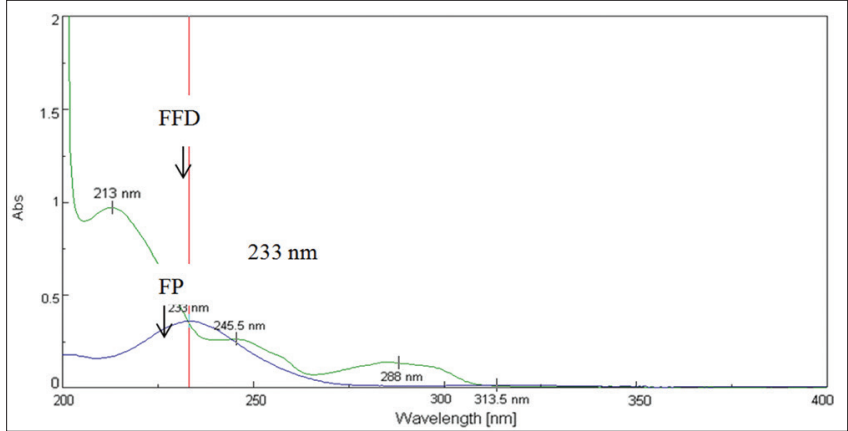

Fig. 2: Overlay spectra for selection of detection wavelength $(233 \mathrm{~nm})$

\section{Optimization of the mobile phase}

Various solvent systems such as mixtures of (1) n-hexane:ethyl acetate:methanol:acetic acid (2.0:2.5:2.0:0.2; v/v/v/v), (2) n-hexane:ethyl acetate:methanol:formic acid (2.0:2.5:2.0:0.2; v/v/v/v), (3) n-hexane:ethyl acetate:acetic acid (5:10:0.2; v/v/v), and (4) toluene:ethylacetate:formicacid(7:3:0.1; v/v/v) weretried toseparate and resolve spots of FFD and FP from each other and other excipients of formulation. The mixture of $n$-hexane:ethyl acetate:methanol:acetic acid (2.0:2.5:2.0:0.2; v/v/v/v) and n-hexane:ethyl acetate:methanol:formic acid (2.0:2.5:2.0:0.2; v/v/v/v) provided well-resolved peaks but tailing was observed. Good peak shape was observed with a mixture of toluene:ethyl acetate:formic acid (7:3:0.1; v/v/v), but the FFD did not resolve from FP. Finally, the mixture of toluene:ethyl acetate:formic acid (6:4:0.1; v/v/v) showed well-resolved peaks with better peak shape. FFD and FP were satisfactorily resolved with $R_{f}$ value $0.27 \pm 0.10$ and $0.64 \pm 0.10$, respectively. Pre-saturation of TLC chamber with the mobile phase for $20 \mathrm{~min}$ assured better reproducibility in the migration of FFD and FP with better resolution which is shown in Fig. 3.

\section{Method validation}

The developed HPTLC method was validated as per the ICH guidelines Q1A (R2), Q1B, Q2 (R1) for linearity, precision, accuracy, limit of detection (LOD), limit of quantification (LOQ), and specificity [28-33].

\section{Linearity}

The linearity of the method was evaluated by constructing calibration curves at six concentration levels. Aliquots of standard working solution of FFD $(1,1.5,2,2.5,3$, and $3.5 \mu \mathrm{L})$ and $(10,20,30,40,50$, and $60 \mu \mathrm{L})$ of FP were applied on the plate, to obtain concentrations of 1, 1.5, 2, $2.5,3$, and $3.5 \mu \mathrm{g} / \mathrm{spot}$ for FFD and 10, 20, 30, 40, 50, and $60 \mu \mathrm{g} / \mathrm{spot}$ for FP. The calibration curves were constructed by plotting peak area versus concentration with the help of Win-CATS software. The plate was developed in a twin trough glass chamber, using 20 min chamber saturation time. The length of the run was $80 \mathrm{~mm}$. The developed plates were air-dried. Scanning was performed in UV mode at $233 \mathrm{~nm}$. The slit dimension was kept at $5 \times 0.45 \mathrm{~mm}$ at a scanning speed of $100 \mathrm{~nm} / \mathrm{s}$. 
Slope, intercept, and coefficient of determination $\left(\mathrm{r}^{2}\right)$ of the calibration curves were calculated to ascertain linearity of the method.

\section{Precision}

To evaluate intraday precision, three samples at three different concentrations were analyzed on the same day. The interday precision was studied by comparing assays performed on three different days.

The precision of an analytical method expresses the degree of scatter between a series of measurements obtained from multiple samples of the same homogeneous sample under prescribed conditions.

The intraday and interday variation for determination of FFD and FP were carried out at three different concentration levels 1.5, 2, and 2.5 $\mu \mathrm{g}$ /spot for FFD and 20, 30, and $40 \mu \mathrm{g}$ /spot for FP.

\section{Repeatability}

Repeatability of sample application was assessed by spotting $2 \mu \mathrm{g} /$ spot for FFD and $30 \mu \mathrm{g} / \mathrm{spot} \mathrm{FP}$ of standard drug solution 6 times on a TLC plate at different times on the same day by sample applicator, followed by the development of plate and recording of the peak areas for six spots.

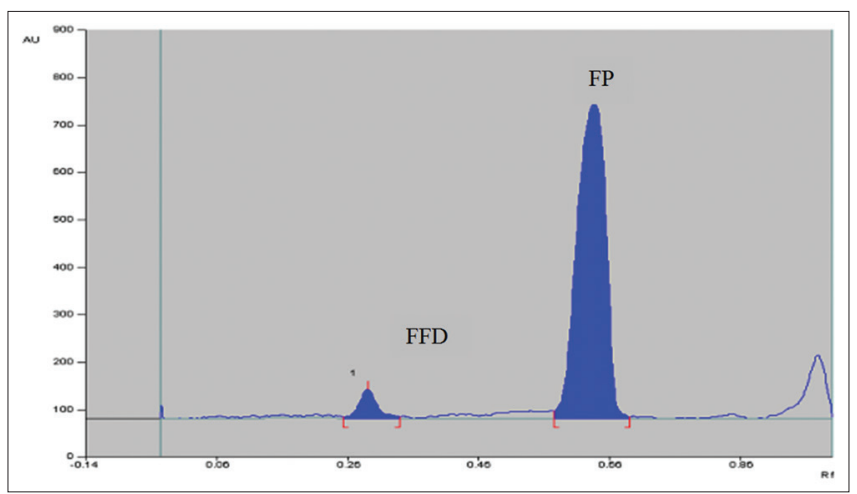

Fig. 3: Typical densitogram of standard formoterol fumarate dihydrate peak $1\left(R_{\mathrm{f}} 0.27\right)$ and fluticasone propionate peak $2\left(R_{f} 0.64\right)$

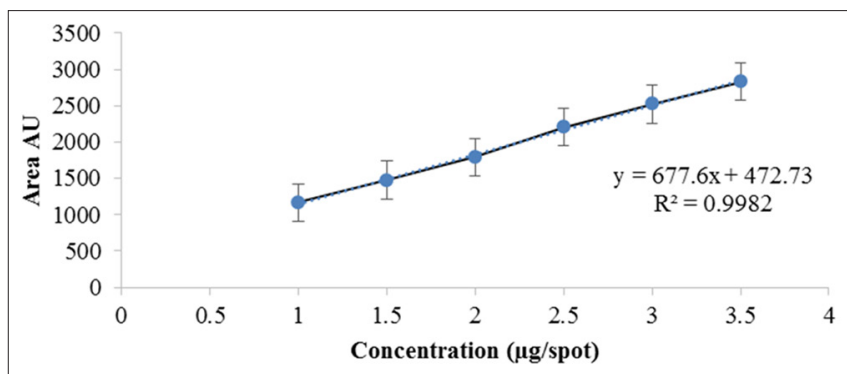

Fig. 4: Calibration curve of formoterol fumarate dihydrate (1-3.5 $\mu \mathrm{g} / \mathrm{spot})$

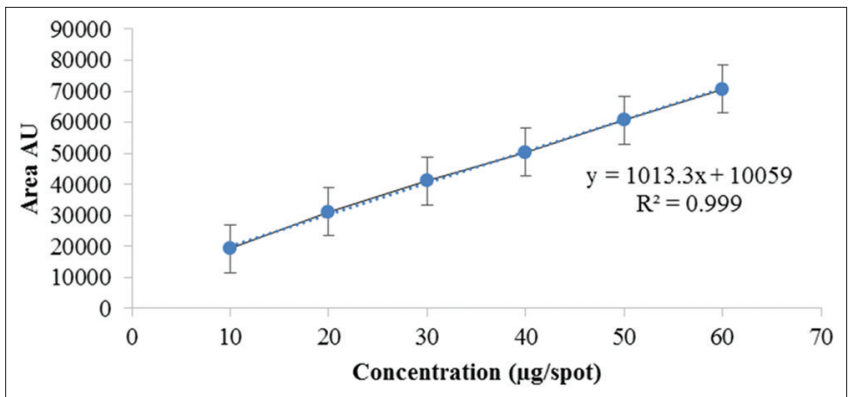

Fig. 5: Calibration curve of fluticasone propionate (10-60 $\mu \mathrm{g} / \mathrm{spot})$
Accuracy

Accuracy studies were carried out at $80-120 \%$ levels, by mixing a known quantity of standard drug $(0.5,0.6$, and $0.7 \mu \mathrm{g}$ for FFD and 8,10 , and $12 \mu \mathrm{g}$ for FP) with the sample formulation and the contents were analyzed by the proposed method.

\section{Specificity}

The specificity of the method was ascertained by analysis of drug standards and samples. The identities of the peaks for FFD and FP were confirmed by comparing the $\mathrm{R}_{\mathrm{f}}$ with those of standards. The peak purity of FFD and FP was assessed by comparing their respective spectra at peak start, peak apex, and peak end positions of the spot.

\section{Robustness}

The proposed HPTLC method was tested for robustness. The parameters selected for the robustness study were, change in the amount of toluene in mobile phase composition, change in time from spotting to chromatography and time from chromatography to scanning, and change in saturation time. By introducing small changes in these parameters, the effect on the results was examined.

\section{Limit of detection (LOD) and limit of quantitation (LOQ)}

LOD and LOQ values represent the sensitivity of the proposed analytical method. To estimate the LOD and LOQ, blank methanol was spotted 6 times. Different concentrations $0.1,0.3,0.5,0.8$, and $1 \mu \mathrm{g}$ /spot for FFD

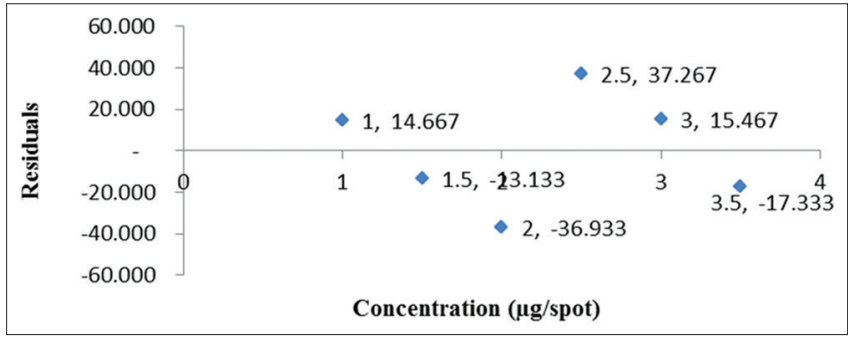

Fig. 6: Residual plot of formoterol fumarate dihydrate

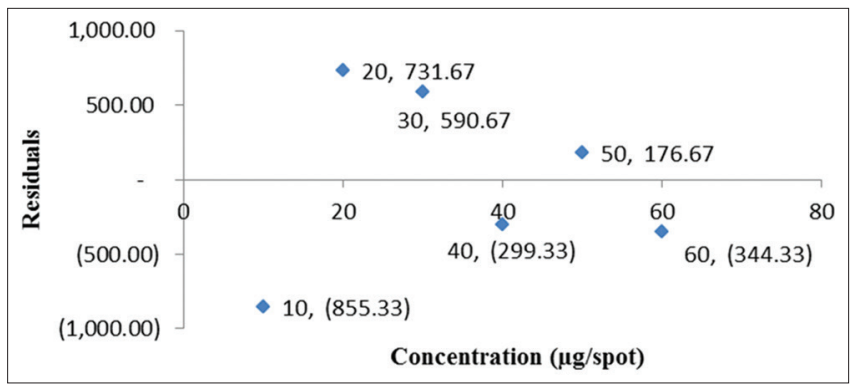

Fig. 7: Residual plot of fluticasone propionate

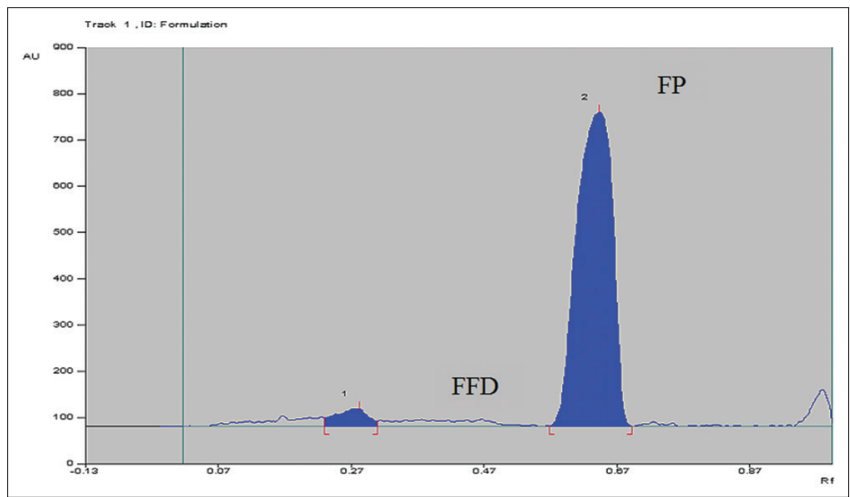

Fig. 8: Typical densitogram of formoterol fumarate dihydrate and fluticasone propionate in the formulation 
and $0.1,0.2,0.4,0.6$, and $0.8 \mu \mathrm{g} /$ spot for FP were spotted. The peak was detected at $0.3 \mu \mathrm{g} /$ spot for FFD and $0.2 \mu \mathrm{g}$ /spot for FP with a signal-tonoise ratio of $3: 1$. The peak was detected with the quantifiable area at $1 \mu \mathrm{g} / \mathrm{spot}$ for FFD and $0.6 \mu \mathrm{g} / \mathrm{spot}$ for FP with a signal-to-noise ratio of 10:1.

\section{Forced degradation studies}

\section{Acid-and base-induced degradation}

To $6 \mathrm{mg}$ of FFD and $100 \mathrm{mg}$ of FP, $10 \mathrm{ml}$ of $0.1 \mathrm{~N} \mathrm{HCl}$ and $10 \mathrm{ml}$ of $0.1 \mathrm{~N}$ $\mathrm{NaOH}$ were added separately and refluxed at $50^{\circ} \mathrm{C}$ for $1 \mathrm{~h}$. Samples were withdrawn $(0.5 \mathrm{ml})$ at different time intervals for $1 \mathrm{~h}$.

Further acidic and alkaline degradation were carried out for a combination of FFD and FP by refluxing them together with 10 $\mathrm{ml} 0.1 \mathrm{~N} \mathrm{HCl}$ and $10 \mathrm{ml} 0.1 \mathrm{~N} \mathrm{NaOH}$ at $50^{\circ} \mathrm{C}$ for $1 \mathrm{~h}$. Samples were withdrawn $(0.5 \mathrm{ml})$ at different time intervals for $1 \mathrm{~h} .3 \mu \mathrm{L}$ solution was applied on TLC plate in such a way that final concentration achieved was $1.8 \mu \mathrm{g} / \mathrm{spot}$ for FFD and $30 \mu \mathrm{g} /$ spot for FP and densitograms were developed.

\section{Oxidative degradation}

To $6 \mathrm{mg}$ of FFD and $100 \mathrm{mg}$ of $\mathrm{FP}, 10 \mathrm{ml}$ of $3 \% \mathrm{H}_{2} \mathrm{O}_{2}$ was added separately and refluxed at $50^{\circ} \mathrm{C}$ for $2 \mathrm{~h}$. Samples were withdrawn $(0.5 \mathrm{ml})$ at different time intervals for $2 \mathrm{~h}$.

Further oxidative degradation was carried out for a combination of FFD and $\mathrm{FP}$ by refluxing them together with $10 \mathrm{ml}$ of $3 \% \mathrm{H}_{2} \mathrm{O}_{2}$ at $50^{\circ} \mathrm{C}$ for 2 h. Samples were withdrawn $(0.5 \mathrm{ml})$ at different time intervals for 2 h. $3 \mu \mathrm{L}$ solution was applied on TLC plate in such a way that final concentration achieved was $1.8 \mu \mathrm{g} /$ spot for FFD and $30 \mu \mathrm{g} / \mathrm{spot}$ for FP and densitograms were developed.

\section{Photolytic degradation}

Solid forms of FFD and FP were exposed directly to sunlight during the daytime for 2 days to study their photolytic stability. Samples were weighed, dissolved and $3 \mu \mathrm{L}$ solution was applied on TLC plate in such a way that final concentration achieved was $1.8 \mu \mathrm{g} / \mathrm{spot}$ for FFD and $30 \mu \mathrm{g} / \mathrm{spot}$ for FP and densitograms were developed.

\section{Neutral hydrolysis}

To $6 \mathrm{mg}$ of FFD and $100 \mathrm{mg}$ of FP, $10 \mathrm{ml}$ of water was added separately and refluxed at $50^{\circ} \mathrm{C}$ for $2 \mathrm{~h}$. Samples were withdrawn $(0.5 \mathrm{ml})$ at different time intervals for $2 \mathrm{~h}$.

Table 1: Linearity and range for FFD and FP

\begin{tabular}{lll}
\hline Linearity and range & FFD & FP \\
\hline Range $(\mu \mathrm{g} / \mathrm{spot})$ & $1-3.5$ & $10-60$ \\
Regression coefficient $\left(\mathrm{r}^{2}\right)$ & 0.998 & 0.999 \\
Linearity equation & $\mathrm{y}=677.6 \mathrm{x}+472.73$ & $\mathrm{y}=1013.3 \mathrm{x}+10059$ \\
\hline
\end{tabular}

FFD: Formoterol fumarate dihydrate, FP: Fluticasone propionate
The neutral degradation of FFD and FP in combination was induced by refluxing them together with $10 \mathrm{ml}$ of water at $50^{\circ} \mathrm{C}$ for $2 \mathrm{~h}$. Samples were withdrawn $(0.5 \mathrm{ml})$ at different time intervals for $2 \mathrm{~h} .3 \mu \mathrm{L}$ solution was applied on TLC plate in such a way that final concentration achieved was $1.8 \mu \mathrm{g} /$ spot for FFD and $30 \mu \mathrm{g} /$ spot for FP and densitograms were developed.

\section{RESULTS}

Optimization of chromatographic conditions

Toluene:ethyl acetate:formic acid (98\%) (6:4:0.1 v/v/v/v) mixture provided best resolution with better peak shape. The $\mathrm{R}_{\mathrm{f}}$ values were found to be 0.27 and 0.64 for FFD and FP, respectively.

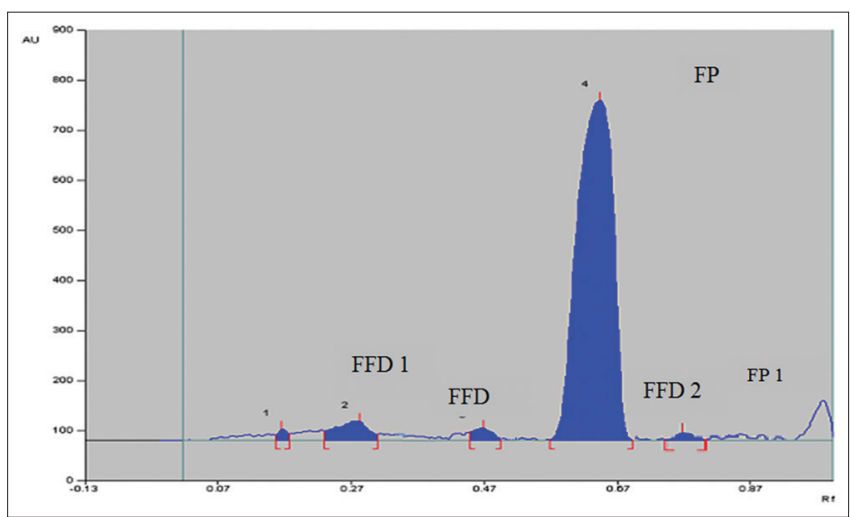

Fig. 9: Densitogram of degradation products of formoterol fumarate dihydrate (FFD) and fluticasone propionate in $0.1 \mathrm{~N} \mathrm{HCL}$ at $50^{\circ} \mathrm{C}$ after $30 \mathrm{~min}$ at $R_{\mathrm{f}}$ value 0.15 (peak 1; FFD 1), 0.47 (peak 3; FFD 2), and 0.72 (peak 5; FP 1), respectively

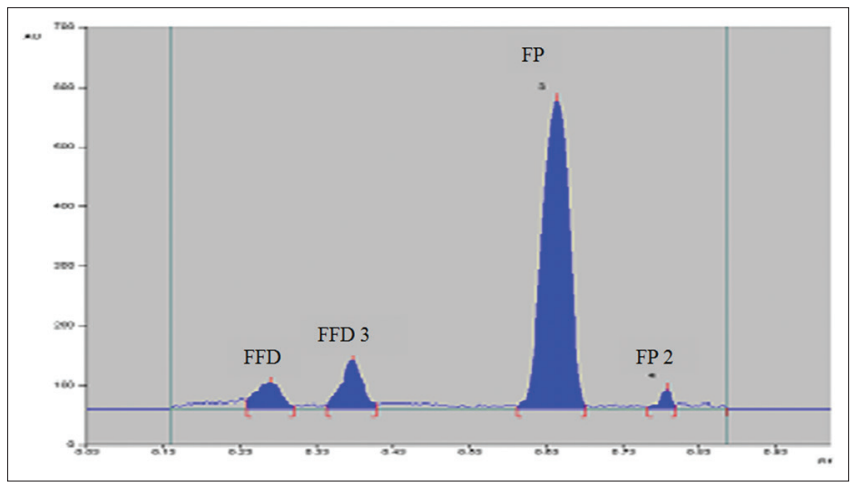

Fig. 10: Densitogram of degradation products of formoterol fumarate dihydrate (FFD) and fluticasone propionate (FP) in $0.1 \mathrm{~N}$ $\mathrm{NaOH}$ at $50^{\circ} \mathrm{C}$ after $15 \mathrm{~min}$ at $\mathrm{R}_{\mathrm{f}}$ value 0.42 (peak 2; FFD 3) and 0.78 (peak 4; FP 2)

Table 2: Precision studies for FFP and FP

\begin{tabular}{|c|c|c|c|c|c|c|c|c|}
\hline Drug & Precision & Concentration ( $\mu \mathrm{g} / \mathrm{spot})$ & Area & & & Average area & Standard deviaton & $\%$ RSD \\
\hline \multirow[t]{6}{*}{ FFD } & Intraday & 1.5 & 1476 & 1452 & 1448 & 1460 & 15.14 & 1.03 \\
\hline & & 2 & 1791 & 1798 & 1757 & 1782 & 21.93 & 1.23 \\
\hline & & 2.5 & 2234 & 2204 & 2252 & 2230 & 24.24 & 1.08 \\
\hline & Interday & 1.5 & 1481 & 1462 & 1498 & 1480 & 18.00 & 1.21 \\
\hline & & 2 & 1771 & 1742 & 1789 & 1767 & 23.71 & 1.34 \\
\hline & & 2.5 & 2267 & 2244 & 2212 & 2241 & 27.62 & 1.23 \\
\hline \multirow[t]{5}{*}{$\mathrm{FP}$} & Intraday & 20 & 38152 & 38869 & 37878 & 38299 & 511.7 & 1.33 \\
\hline & & 40 & 57998 & 57993 & 56901 & 57630 & 631.9 & 1.09 \\
\hline & Interday & 20 & 38282 & 37895 & 37248 & 37808 & 522.4 & 1.38 \\
\hline & & 30 & 47989 & 48102 & 48966 & 48322 & 566.9 & 1.17 \\
\hline & & 40 & 57767 & 56894 & 56587 & 57082 & 612.2 & 1.07 \\
\hline
\end{tabular}

FFD: Formoterol fumarate dihydrate, FP: Fluticasone propionate, RSD: Relative standard deviation 
Validation of the method Linearity (calibration curve)

Linearity was demonstrated with six different concentration levels for both FFD and FP, which were found to be linear in the range of 1-3.5 $\mu \mathrm{g} / \mathrm{spot}$ for FFD and 10-60 $\mu \mathrm{g}$ /spot for FP. The values are given in Table 1. Regression coefficient and concentration of the drugs correlated well. The calibration curves are shown in Figs. 4 and 5. The residual plots are shown in Figs. 6 and 7.

\section{Precision}

The values of intraday and interday precision are given against sample application and scanning of peak area and results are expressed in terms of percentage relative standard deviation (RSD). The measurement of peak areas at three different concentration levels showed a low value of percentage RSD $(<2)$ for intra- and inter-day variation, which suggested that the method was precise (Table 2).

\section{Repeatability}

The percentage RSD for repeatability of the drugs was found to be $<2$ (i.e., 1.05 for FFD and 1.17 for FP). Hence, it was concluded that the proposed method for estimation of FFD and FP was repeatable in nature; the data for the same are shown in Table 3.

Table 3: Repeatability study for FFD and FP $(n=6)$

\begin{tabular}{lllll}
\hline Drug & $\begin{array}{l}\text { Concentration } \\
(\mu \mathrm{g} / \text { spot) }\end{array}$ & Peak area & Average area & \% RSD \\
\hline Formoterol & 2 & 1763 & 1773.33 & 1.05 \\
fumarate & 2 & 1748 & & \\
dihydrate & 2 & 1768 & & \\
& 2 & 1774 & & \\
& 2 & 1802 & & \\
Fluticasone & 30 & 1785 & & \\
propionate & 30 & 48369 & 48707.16 & \\
& 30 & 49435 & & \\
& 30 & 47885 & & \\
& 30 & 48598 & & \\
& 30 & 48687 & & \\
\end{tabular}

FFD: Formoterol fumarate dihydrate, FP: Fluticasone propionate, RSD: Relative standard deviation
Accuracy

To check the accuracy of the method, recovery studies were carried out by standard addition of drug solution to pre-analyzed sample solution at

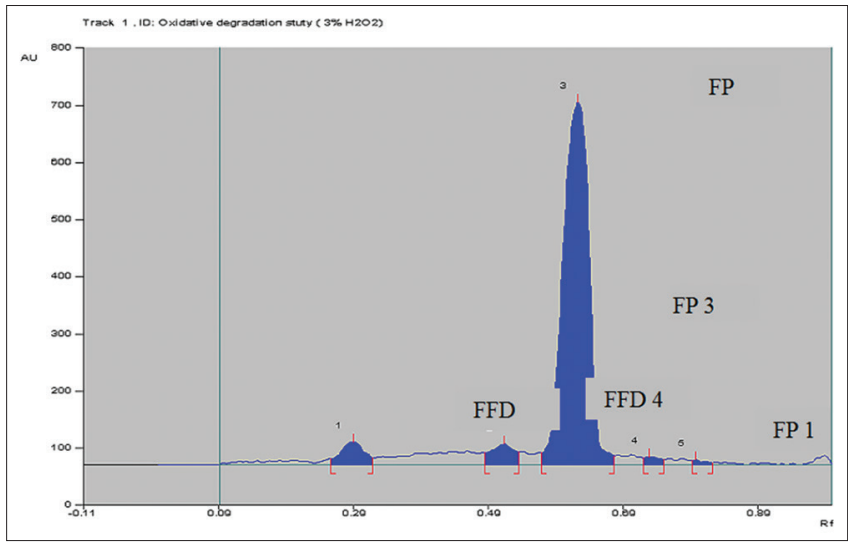

Fig. 11: Densitogram of degradation products of formoterol fumarate dihydrate (FFD) and fluticasone propionate (FP) in 3\% $\mathrm{H}_{2} \mathrm{O}_{2}$ at $50^{\circ} \mathrm{C}$ after $1 \mathrm{~h}$ at $\mathrm{R}_{\mathrm{f}}$ value 0.50 (peak 2; FFD 4) for FFD and 0.72 (peak 4; FP 1), 0.84 (peak 5; FP 3) for FP

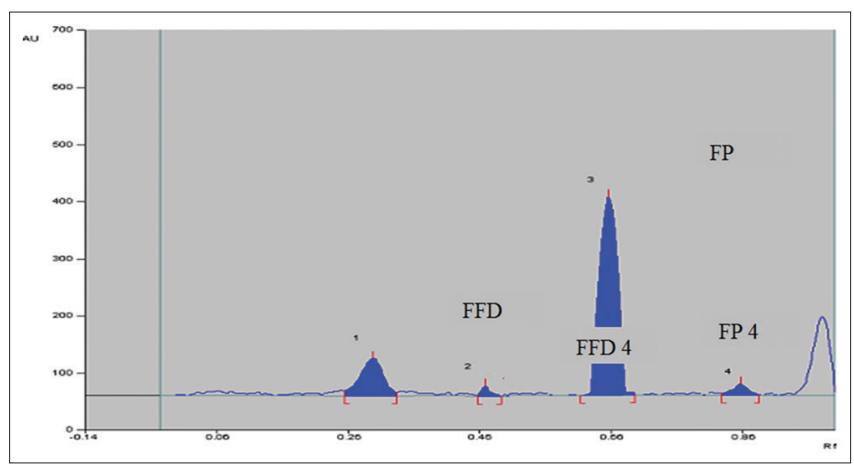

Fig. 12: Densitogram of degradation products of formoterol fumarate dihydrate (FFD) and fluticasone propionate (FP) after exposure of solid drugs direct to sunlight during daytime for 2 days at $R_{\mathrm{f}}$ value 0.48 (peak 2; FFD 4) and 0.85 (peak 4; FP 4)

Table 4: Recovery studies for FFD and FP by HPTLC method $(n=3)$

\begin{tabular}{|c|c|c|c|c|c|c|c|c|}
\hline \multirow{2}{*}{$\begin{array}{l}\text { Label claim } \\
(\mu \mathrm{g} / \text { capsule })\end{array}$} & \multirow{2}{*}{$\begin{array}{l}\text { \% Level of spiked } \\
\text { standard drug }\end{array}$} & \multicolumn{3}{|c|}{ Conc. added } & \multirow{2}{*}{$\begin{array}{l}\text { Average area } \\
n^{*}=3\end{array}$} & \multirow{2}{*}{$\begin{array}{l}\text { Amount } \\
\text { recovered }(\mu \mathrm{g})\end{array}$} & \multirow[t]{2}{*}{ \% Recovery } & \multirow{2}{*}{$\begin{array}{l}\text { Mean }(\%) \\
\text { recovery }\end{array}$} \\
\hline & & Formulation & Pure drug & Total amount $(\mu \mathrm{g})$ & & & & \\
\hline \multirow[t]{2}{*}{ FFD $6 \mu \mathrm{g}$} & 80 & 0.6 & 0.5 & 1.1 & 1212 & 1.09 & 99.09 & 99.13 \\
\hline & 120 & 0.6 & 0.7 & 1.3 & 1348 & 1.29 & 99.23 & \\
\hline \multirow{3}{*}{ FP $100 \mu \mathrm{g}$} & 80 & 10 & 8 & 18 & 28136 & 17.83 & 99.05 & 99.22 \\
\hline & 100 & 10 & 10 & 20 & 30195 & 19.87 & 99.35 & \\
\hline & 120 & 10 & 12 & 22 & 32196 & 21.84 & 99.27 & \\
\hline
\end{tabular}

FFD: Formoterol fumarate dihydrate, FP: Fluticasone propionate, RSD: Relative standard deviation, HPTLC: High-performance thin-layer chromatography

Table 5: Results of robustness evaluation of FFD and FP ( $n=3$ )

\begin{tabular}{|c|c|c|c|c|}
\hline \multirow[t]{2}{*}{ Condition } & \multicolumn{2}{|c|}{ FFD } & \multicolumn{2}{|c|}{ FP } \\
\hline & Average area & \% RSD & Average area & $\%$ RSD \\
\hline \multicolumn{5}{|l|}{ A: Change in amount of toluene in mobile phase composition } \\
\hline Toluene: ethyl acetate: formic acid(5.9:4:0.1\% v/v/v) & 1413 & 1.13 & 57047 & 1.14 \\
\hline Toluene: ethyl acetate: formic acid (6.1:4:0.1\% v/v/v) & 1471 & 1.12 & 57006 & 1.12 \\
\hline \multicolumn{5}{|l|}{ B: Change in saturation time (min) } \\
\hline $15 \mathrm{~min}$ & 1433 & 1.10 & 56953 & 1.13 \\
\hline C: Time from spotting to chromatography (+10 min) & 1433 & 1.10 & 56833 & 1.10 \\
\hline D: Time from chromatography to scanning (+10 min) & 1407 & 1.13 & 57426 & 1.11 \\
\hline
\end{tabular}

FFD: Formoterol fumarate dihydrate, FP: Fluticasone propionate, RSD: Relative standard deviation 
three different levels 80,100 , and $120 \%$. The percent mean recoveries were found to be $99.13 \%$ for FFD and $99.22 \%$ for FP (Table 4 ).

\section{Specificity}

The peak purity of FFD and FP was assessed by comparing their respective densitograms at peak start, peak apex, and peak end positions of the spot, i.e., $\mathrm{r}$ (start, middle $)=(0.25-0.27)$ and $\mathrm{r}$ (middle, end $)=$ $(0.27-0.29)$ for FFD and $r$ (start, middle) $=(0.57-0.65)$ and $r$ (middle, end $)=(0.65-0.68)$ for FP. The chromatogram of capsule sample showed peaks at $R_{f}$ values of 0.27 and 0.64 for FFD and FP, respectively (Fig. 8), indicating that there is no interference of the excipients present in the capsule formulation indicating the specificity of the method.

\section{Robustness}

The percentage RSD of the peak areas was calculated for change in the amount of toluene in mobile phase composition, change in time from spotting to chromatography and time from chromatography to scanning, change in saturation time and change in solvent run distance (Table 5).

\section{Limits of detection and quantitation}

The LOD is the smallest concentration of the analyte that gives a measurable response (signal to noise ratio of 3:1). The LOD was found to be $0.3 \mu \mathrm{g} /$ spot for FFD and $0.2 \mu \mathrm{g} /$ spot for FP. LOQ is the smallest concentration of the analyte, which gives the response that can be

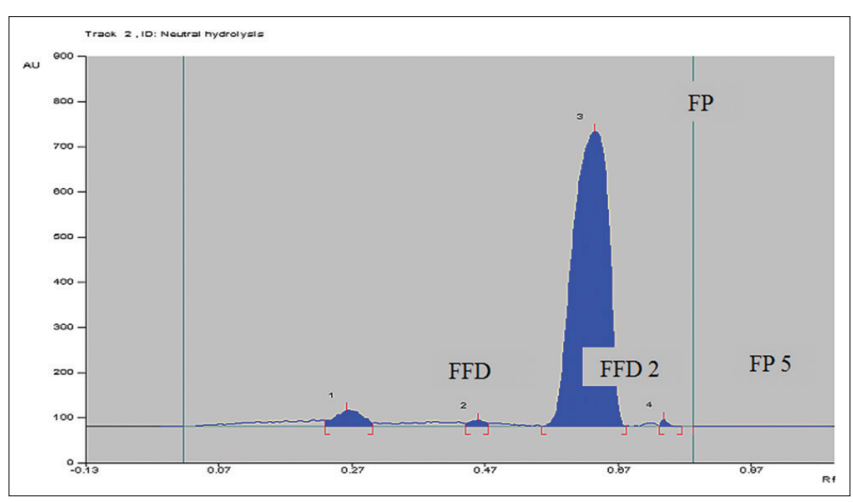

Fig. 13: Densitogram of degradation products of formoterol fumarate dihydrate (FFD) and fluticasone propionate (FP) in neutral hydrolysis after 30 min at $R_{\mathrm{f}}$ value 0.47 (peak 2; FFD 2) and 0.74 (peak 4; FP 5)

Table 6: Results of LOD and LOQ

\begin{tabular}{lll}
\hline Drug & LOD $(\mu \mathrm{g} /$ spot $)$ & LOQ $(\mu \mathrm{g} / \mathrm{spot})$ \\
\hline FFD & 0.3 & 1 \\
FP & 0.2 & 0.6
\end{tabular}

FFD: Formoterol fumarate dihydrate, FP: Fluticasone propionate, LOD: Limit of detection, LOQ: Limit of quantification accurately quantified (signal to noise ratio of 10:1). The LOQ was $1 \mu \mathrm{g} /$ spot for FFD and $0.6 \mu \mathrm{g} /$ spot for FP, which indicates that the proposed method was sensitive enough to detect the drugs at very low concentration level (Table 6)

\section{Forced degradation studies}

Selectivity of the method was demonstrated by enhancing degradation of FFD and FP under various stressed conditions (acid, base hydrolysis, oxidation, neutral, and photochemical), to show that FFD and FP were separated from their possible degradation products. The number of degradation products with their $\mathrm{R}_{\mathrm{f}}$ was calculated and listed in Table 7.

\section{Acid-induced degradation}

The densitograms for acid degraded FFD and FP showed additional peaks at $\mathrm{R}_{\mathrm{f}} 0.15,0.47$ and 0.72 , respectively. The rate of degradation for FFD (18.00\%) was more as compared to FP (13.22\%) in acid-induced degradation (Fig. 9).

\section{Base-induced degradation}

The degradation in $10 \mathrm{ml}$ of $0.1 \mathrm{~N} \mathrm{NaOH}$ at $50^{\circ} \mathrm{C}$ was so fast that around $18.12 \%$ of $\mathrm{FP}$ was degraded in $15 \mathrm{~min}$, forming one degradation product at $\mathrm{R}_{\mathrm{f}} 0.78$ and $9.11 \%$ of FFD was degraded with one degradation product at $\mathrm{R}_{\mathrm{f}}$ value 0.42 (Fig. 10).

\section{Oxidative degradation}

The drugs were found to be susceptible to oxidative degradation. The densitogram of hydrogen peroxide-induced degradation showed the additional peaks at $\mathrm{R}_{\mathrm{f}}$ value 0.50 for FFD and 0.72 and 0.84 for FP, respectively. The percent of degradation was found to be $13.06 \%$ for FFD and $11.29 \%$ for FP (Fig. 11).

\section{Photolytic degradation}

FP and FFD were found to undergo photolytic degradation after exposure of solid drugs direct to sunlight during the daytime for 2 days. Degradation of FFD was observed (5.74\%) with degradation product at $\mathrm{R}_{\mathrm{f}}$ value 0.48 and $18.37 \%$ degradation was observed for FP with an additional peak at $\mathrm{R}_{\mathrm{f}}$ value 0.85 (Fig. 12).

\section{Neutral degradation}

The FFD and FP showed two additional peaks when treated in water at $50^{\circ} \mathrm{C}$ for $30 \mathrm{~min}$. Peaks of degraded products were found at $\mathrm{R}_{\mathrm{f}}$ value 0.47 for FFD and 0.74 for FP (Fig. 13).

\section{DISCUSSION}

The proposed stability indicating HPTLC method provides precise, accurate, and reproducible quantitative analysis for simultaneous estimation of FFD and FP in bulk drug and pharmaceutical dosage form. The method was validated as per the ICH guidelines. The linearity was found to be in the range of 1-3.5 $\mu \mathrm{g} / \mathrm{spot}$ and 10-60 $\mu \mathrm{g} / \mathrm{spot}$ for FFD and FP, respectively. Percentage RSD of intraday and interday precision was found to be $<2 \%$ making the method more precise. Degradation study revealed that FFD was most prone to degradation under acid $(18 \%, 30 \mathrm{~min})$ stress followed by the stress conditions such as neutral

Table 7: Summary of degradation studies for FFD and FP

\begin{tabular}{|c|c|c|c|c|c|c|}
\hline \multirow[t]{2}{*}{ Stressed condition } & \multicolumn{3}{|c|}{ FFD } & \multicolumn{3}{|c|}{ FP } \\
\hline & Rf (FFD) & \% Degradation & DP of FFD at Rf & Rf (FP) & \% Degradation & DP of FP at Rf \\
\hline Acid, $0.1 \mathrm{~N} \mathrm{HCl}$ at $50^{\circ} \mathrm{C}$ after $30 \mathrm{~min}$ & 0.26 & 18.00 & $\begin{array}{l}\text { FFD 1-0.15, } \\
\text { FFD 2-0.47 }\end{array}$ & 0.64 & 13.22 & FP 1-0.72 \\
\hline Base, $0.1 \mathrm{~N} \mathrm{NaOH}$ at $50^{\circ} \mathrm{C}$ after $15 \mathrm{~min}$ & 0.26 & 9.11 & FFD 3-0.42 & 0.63 & 18.12 & FP 2-0.78 \\
\hline Oxidative, $3 \% \mathrm{H}_{2} \mathrm{O}_{2}$ at $50^{\circ} \mathrm{C}$ after $1 \mathrm{~h}$ & 0.27 & 13.06 & FFD 4-0.50 & 0.63 & 11.29 & $\begin{array}{l}\text { FP 1-0.72, } \\
\text { FP 3-0.81 }\end{array}$ \\
\hline Neutral, distilled water at $50^{\circ} \mathrm{C}$ after $30 \mathrm{~min}$ & 0.27 & 14.34 & FFD 2-0.47 & 0.64 & 13.22 & FP 5-0.74 \\
\hline
\end{tabular}

FFD: Formoterol fumarate dihydrate, FP: Fluticasone propionate, DP: Degradation product 
(14.3\%, $30 \mathrm{~min})$, base $(9.11 \%, 15 \mathrm{~min})$, oxidative $(13.06 \%, 1 \mathrm{~h})$, and photolytic (5.74\%, 2 days). FP showed more degradation in basic $(18.12,15 \mathrm{~min})$ and photolytic $(18.3 \%, 24 \mathrm{~h})$ conditions.

\section{CONCLUSION}

The developed method was able to separate the drugs from its degradants and impurities. It can be successfully applied as stability indicating method for combination of FFD and FP. Thus, the reported method is of considerable importance and has sound industrial applicability for quality control and stability analysis of FFD and FP from bulk drug and pharmaceutical dosage form.

\section{ACKNOWLEDGMENTS}

Authors are thankful to Vamsi Laboratories Pvt. Ltd. Solapur, Maharashtra, India, for providing gift samples of formoterol fumarate dihydrate and fluticasone propionate.

\section{AUTHORS' CONTRIBUTIONS}

Rajashi B. Pharate - Department of Quality Assurance, Bharati Vidyapeeth University, Poona College of Pharmacy, Pune - 411038, Maharashtra, India. Suneela S Dhaneshwar - Amity Institute of Pharmacy, Amity University Uttar Pradesh, Lucknow, Uttar Pradesh, India.

\section{CONFLICTS OF INTEREST}

The authors declare that they have no conflicts of interest.

\section{REFERENCES}

1. Scichilone N, Rossi A, Melani A. Revising old principles of inhaled treatment in new fixed combinations for asthma. Pulm Pharmacol Ther 2015;33:32-8

2. Available from: htpp://www.drugbank.com.

3. Available from: htpp://www.en.wikipedia.org/wiki/Formoterol FumarateDihydrate.

4. Available from: htpp://www.en.wikipedia.org/wiki/Fluticasone Propionate.

5. The Indian Pharmacopoeia. The Indian Pharmacopoeia Commission. $6^{\text {th }}$ ed., Vol. 2, Ghaziabad: The Indian Pharmacopoeia; 2010. p. 1382-4, 1386-7.

6. British Pharmacopoeia Commission. British Pharmacopoeia. Vol. 2. London: Her Majestry's Stationary Office; 2013. p. 974-6, 984-6.

7. United States Pharmacopoeia Convention. United States Pharmacopoeia 30. National Formulary 25. Vol. 2. Rockville, USA: United States Pharmacopoeia Convention; 2013. p. 3653-7, 3669-70.

8. Council of Europe. European Pharmacopoeia 7.2. European Directorate for the Quality of Medicine and Healthcare. Vol. 2. Strasbourg: Council of Europe; 2010. p. 2059-2060, 2067-69.

9. Malik K, Kumar D. Simultaneous quantitative determination of formoterol fumarate and fluticasone propionate by validated reversedphase HPLC method in metered dose inhaler. Pharm Sinica 2011;2: 77-84.

10. Raval PP, Dave JB. Estimation of fluticasone propionate in nasal preparation and in combination with formoterol furamate in inhalation preparation. World J Pharm Pharm Sci 2014;3:1148-60.

11. Assi KH, Tarsin W, Chrystyn H. High performance liquid chromatography assay method for simultaneous quantitation of formoterol and budesonide in symbicort turbuhaler. J Pharm Biomed Anal 2006;41:325-8

12. Akapo SO, Asif M. Validation of a RP-HPLC method for the assay of formoterol and its related substances in formoterol fumarate dihydrate drug substance. J Pharm Biomed Anal 2003;33:935-45.

13. Shah BD, Yadav YC. Analytical method development and method validation of tiotropium bromide and formoterol fumarate metered dose inhaler by using RP-HPLC method. Asian J Biochem Pharm Res 2011;1:145-58.

14. Kale NR, Pingle AP. Development and validation of stability indicating RP-HPLC method for simultaneous estimation of formoterol fumarate and budesonide in metered dose inhaler formulation. World J Pharm Res 2014;3:1386-99.

15. Patil AT, Patil SD. Sensitive LC method for simultaneous determination of ciclesonide and formoterol fumarate in dry powder inhaler. J Liq Chromatogr Relat Technol 2011;34:1568-77.

16. Srinivasaro K, Gorule V. Validated method development for estimation of formoterol fumarate and mometasone furoate in metered dose inhalation form by high performance liquid chomatography. J Anal Bioanal Tech 2012;3:1-4

17. Gujrati PZ, Thula KC. Stability indicating HPLC method for simultaneous estimation of mometasone furoate and formoterol fumarate in combined dosage form. Pharmacophore 2014;5:219-30.

18. Samir A, Salem H. simultaneous determination of salmeterol xinafoate and fluticasone propioanate in bulk powder and seritide diskus by HPLC. Pharm Anal Acta 2012:3:1-7.

19. Parmar VK, Patel HN. Sensitive and robust methods for simultaneous determination of beclomethasone dipropionate and formoterol fumarate dihydrate in rotacaps. J Chom Sci 2014;52:1255-66.

20. Dave HN, Makwana AG. Validated HPTLC method for the determination of two novel steroids in bulk and pressurized metered dose preparations. Int J Appl Sci Eng 2011;9:177-85.

21. Kondawar MS, Shah RR. UV spectrophotometric method for simultaneous estimation of salmeterol xinafoate and fluticasone propionate in bulk and dosage form. Int J Pharm Tech Res 2011;3:1801-6.

22. Zanwar AS, Sen DB. Spectroscopic method for simultaneous estimation of mometasone furoate and formoterol in rotocaps. Indo Am J Pharm Res 2014;4:5928-33

23. Prasad AV. Simultaneous spectrophotometric determination of formoterol fumarate and budesonide in their combined dosage form. Indian J Chem Technol 2006;13:81-3.

24. Mohd G, Appala S. Development and validation of spectrometric methods for estimation of formoterol bulk drug and its dosage form. Int J Pharm Pharm Sci 2011;3:306-9.

25. Samir A, Salem H. New developed spectrophotometric method for simultaneous estimation of salmeterol xinafoate and fluticasone propionate in bulk powder and seritide diskus inhalation. Bull Faculty Pharm 2012;50:121-6.

26. Kasaye L, Hymete A, Mohamed AM. HPTLC-densitometric method for simultaneous determination of salmeterol xinafoate and fluticasone propionate in dry powder inhalers. Saudi Pharm J 2010;18:153-9.

27. Gowekar NM, Wadher SJ. Simultaneous estimation of formoterol fumarate dihydrate and fluticasone propionate in dry powder inhalation formulation by HPTLC. Pharma Chem 2016;8:27-32.

28. International Conference on Harmonization. Q2B. Validation of Analytical Procedure: Methodology. Geneva: International Conference on Harmonization; 1996.

29. ICH Harmonized Tripartite Guideline. Validation of Analytical Procedure: Text and Methodology Q2 (R1). Geneva: International Conference on Harmonization; 2005.

30. International Conference on Harmonisation (ICH) Guidelines. Q1A (R2) for Stability Testing of New Drug Substances and Products. Geneva, Switzerland: International Conference on Harmonization; 2003.

31. International Conference on Harmonization (ICH) Guidelines. Q1B for Stability Testing: Photo-stability Testing of New Drug Substances and Products. Geneva, Switzerland: International Conference on Harmonization; 1996.

32. Shinde CC, Chopade S, Dhaneshwar SS. Development and validation of HPTLC method for estimation of voglibose in pharmaceutical dosage forms. Int J Pharm Pharm Sci 2015;7:288-93.

33. Chudiwal SS, Dehghan MH. Analytical method development and validation for quantification of flunisolide in nasal spray formulation by RP-HPLC. Int J Pharm Pharm Sci 2016;8:141-6 